This item was submitted to Loughborough's Research Repository by the author.

Items in Figshare are protected by copyright, with all rights reserved, unless otherwise indicated.

\title{
Kinetic studies of liquid phase ethyl tert-butyl ether (ETBE) synthesis using macroporous and gelular ion exchange resin catalysts
}

PLEASE CITE THE PUBLISHED VERSION

\section{PUBLISHER}

(C) Elsevier

\section{VERSION}

AM (Accepted Manuscript)

\section{LICENCE}

CC BY-NC-ND 4.0

\section{REPOSITORY RECORD}

Umar, M., Dipesh Patel, and Basu Saha. 2009. "Kinetic Studies of Liquid Phase Ethyl Tert-butyl Ether (ETBE) Synthesis Using Macroporous and Gelular lon Exchange Resin Catalysts". figshare. https://hdl.handle.net/2134/5416. 
This item was submitted to Loughborough's Institutional Repository (https://dspace.lboro.ac.uk/) by the author and is made available under the following Creative Commons Licence conditions.

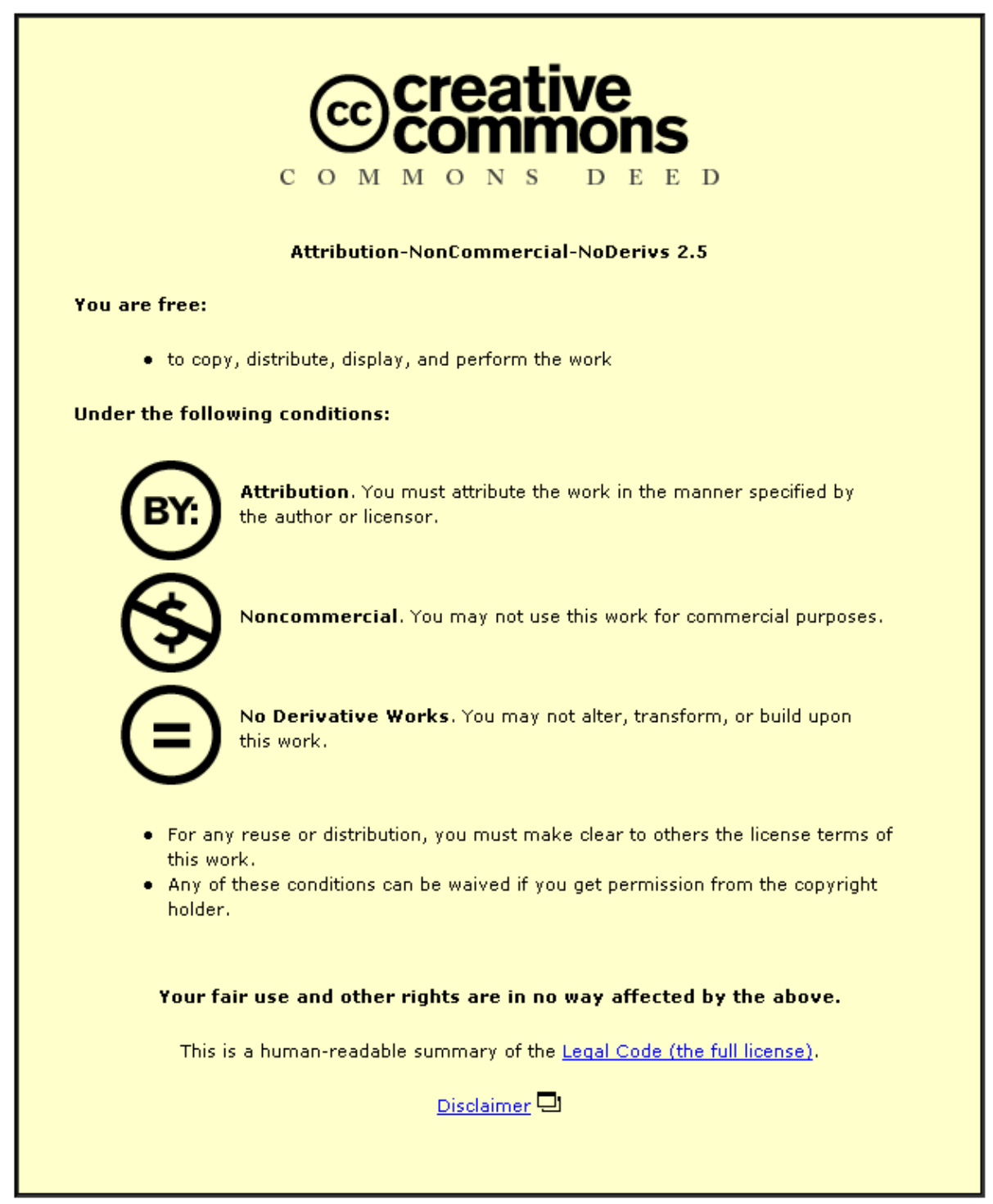

For the full text of this licence, please go to: http://creativecommons.org/licenses/by-nc-nd/2.5/ 


\title{
Kinetic studies of liquid phase ethyl tert-butyl ether (ETBE) synthesis using macroporous and gelular ion exchange resin catalysts
}

\author{
M. Umar ${ }^{\mathrm{b}, \#}$, D. Patel ${ }^{\mathrm{a}}$, B. Saha ${ }^{\mathrm{a},{ }^{,}}$ \\ ${ }^{a}$ Department of Chemical Engineering Loughborough University, Loughborough, Leicestershire, LE11 3TU, UK \\ ${ }^{b}$ Department of Chemical Engineering, University of Engineering \& Technology, Lahore, 54890, Pakistan
}

Ethyl tert-butyl ether (ETBE) synthesis from ethanol (EtOH) and tert-butyl alcohol (TBA) was studied with different macroporous and gelular ion exchange resin catalysts. Purolite $^{\circledR}$ (CT-124, CT-145H, CT-151, CT-175 and CT-275) and Amberlyst $^{\circledR}$ (15 and 35) ion exchange resins were used for the present work. Effect of various parameters such as catalyst type, temperature, reactants feed molar ratio and catalyst loading were studied for the optimisation of reaction condition. Among the catalysts studied, Purolite CT-124 gave better results for TBA conversion and selectivity towards ETBE. Kinetic modelling was performed with this catalyst and activation energy and water inhibition coefficient were determined. Heterogeneous kinetic models [e.g., Eley-Rideal (ER), Langmuir-Hinshelwood-Hougen-Watson (LHHW)] were unable to predict the behaviour of this etherification reaction, whilst the quasi-homogeneous $(\mathrm{QH})$ model represented the system very well over wide range of reaction conditions.

Keywords: ETBE synthesis; Kinetics; Ion Exchange resins; Catalysis; Reaction Engineering.

\footnotetext{
${ }^{*}$ Corresponding author. Email: B.Saha@lboro.ac.uk (Dr B Saha)

\# Worked as a visiting research student at Loughborough University, UK during this project.
} 


\section{Introduction}

The stringent environmental protection regulation agencies have restricted the usage of lead compounds (e.g., tetra-ethyl lead and tetra-methyl lead) as octane enhancers in most parts of the world. The emphasis was therefore given to alternate sources for increasing octane number as well as the oxygen content of the gasoline fuels. The tertiary ethers like methyl tert-butyl ether (MTBE), ethyl tert-butyl ether (ETBE) and tert-amyl methyl ether (TAME) were considered to be the most suitable and preferred sources over alcoholic oxygenates (e.g., methanol, ethanol and tert-butanol) due to their low Blending Reid vapour pressure (BRvp), higher octane number and low solubility in water. Among these ethers, ETBE was considered to be a better option due to its characteristics of higher octane rating (111), low BRvp (27.56 KPa) and reasonably high oxygen contents (15.7 wt \%) (Yang et al., 2000).

The synthesis of ETBE using iso-butylene (IB) and ethanol (EtOH) as reactants was reported in the literature (Bisowarno and Tade, 2000; Fite et al., 1994; Sneesby et al., 1997; Tade and Tian, 2000). However, recently more emphasis was given to direct synthesis of ETBE using ethanol (EtOH) and tert-butyl alcohol (TBA) in liquid phase. TBA was preferred to IB as the latter was limited to catalytic cracking and it will be difficult for IB to fulfil its future requirements for ethers production. Moreover, TBA is relatively less expensive as it is a major by-product in ARCO process for the production of propylene oxide (Matouq et al., 1993). Various catalysts such as $\beta$ zeolites (Assabumrungrat et al., 2002, Assabumrungrat al., 2004), heteropoly acid (Yin et al., 1995), ion exchange resins [e.g. S-54 and D-72 (Yang et al., 2000) and Amberlyst-15 (Quitain et al., 1999)], potassium hydrogen sulphate (Matouq et al., 1996) etc. have been employed for ETBE synthesis from TBA and EtOH. 
The aim of the present study is to explore the catalytic efficacy of different ion exchange resin catalysts other than those mentioned above which has not been investigated previously for etherification reactions. These new ion exchange resins catalysts include macroporous [e.g., (Purolite CT-145H, CT-151, CT-175 and CT-275) and (Amberlyst 15 and 35)] as well as gelular resin (Purolite CT-124). Amberlyst 15 and Amberlyst 35 are referred to as A-15 and A-35, respectively. The detailed liquid phase batch kinetics for optimising the TBA conversion and ETBE selectivity have been compared with all the new catalysts.

\section{Experimental}

\section{Materials and Catalysts}

TBA $(99.5 \%$, GLC), ethanol $(99.8 \%$, GC) and ETBE $(97 \%$, GC) were purchased from Fisher Scientific, UK and their purity was verified by gas chromatography. Cation exchange resin catalysts, Amberlyst resins (A-15 and A-35) were provided by Rohm and Haas, France and Purolite resins (CT-124, CT-145H, CT-151, CT-175 and CT275) were supplied by Purolite International Limited, UK. Ion exchange resin catalysts were washed thoroughly with de-ionized water and then with methanol to remove any sorbed water and impurities present in the resin. Washed and atmospherically dried catalysts were kept in vacuum oven at $373 \mathrm{~K}$ for six hours to remove any residual moisture. Washed and dried resins were stored in desiccators for further use. Catalysts were characterized using Brunner-Emmett-Teller (BET) surface area and Langmuir surface area measurement, particle size distribution, pore size and pore volume distribution, scanning electron microscopy (SEM) for surface and inner particle structure, bulk and true density measurement and elemental analysis. 


\section{Apparatus}

A five necked flat bottom round top jacketed reaction vessel of $5.0 \times 10^{-4} \mathrm{~m}^{3}$ was used to carry out the experiments. Mechanical stirrer was fixed in the central neck and other necks were used for condenser, thermocouple, catalyst feeding and sampling. A water bath with temperature controller was used to keep the contents of reaction vessel at desired temperature.

\section{Procedure}

Measured quantities of reactants (TBA and EtOH) were fed to the jacketed reaction vessel and the contents were heated to the desired reaction temperature. The catalyst was added to the reaction mixture when the reaction mixture reached the required temperature. This time was noted as zero (i.e. $\mathrm{t}=0$ ). Samples were taken at regular intervals until the reaction attained equilibrium (i.e. for about 6.5 hours) and were analysed by gas chromatograph (GC).

\section{Analysis}

Samples were analysed by Pye Unicam 104 gas chromatograph (GC) equipped with Supelco $^{\circledR}$ PORAPAK-Q (80/100) column of $1.83 \mathrm{~m}$ length and $3.175 \times 10^{-6} \mathrm{~m}$ diameter and thermal conductivity detector (TCD). Helium gas of $99.9 \%$ purity was used as the mobile phase at $2.5 \mathrm{Kg} / \mathrm{cm}^{2}$ pressure and $0.60 \mathrm{~cm}^{3} / \mathrm{s}$ flow rate. The temperature programme was set as hold at $373 \mathrm{~K}$ for first five minutes and then ramp of $25 \mathrm{~K} / \mathrm{min}$ was set and maximum temperature of oven was set at $458 \mathrm{~K}$. Injector and detector temperatures were set isothermal at $458 \mathrm{~K}$. Separation was achieved for all components. 
To establish accuracy, reliability and reproducibility of the collected data, all experiments (except SEM image analysis) were conducted in duplicate. Each GC analysis was replicated three times and the relative error for analytical procedures was less than $3 \%$.

\section{Reaction Chemistry and Mechanism}

In the synthesis of ETBE from TBA and ethanol (EtOH), following sequence of reactions take place:

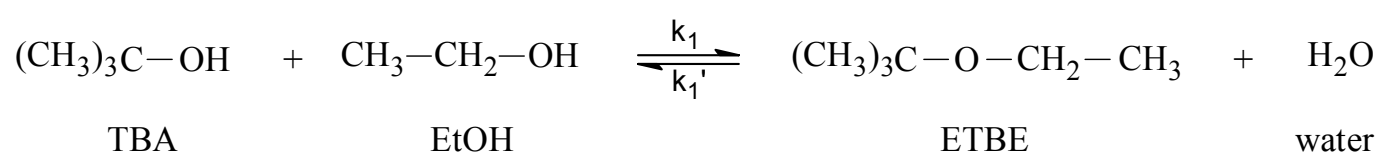

The above main reaction is accompanied by the side reaction, i.e. dehydration of TBA into iso-butylene (IB) and water.

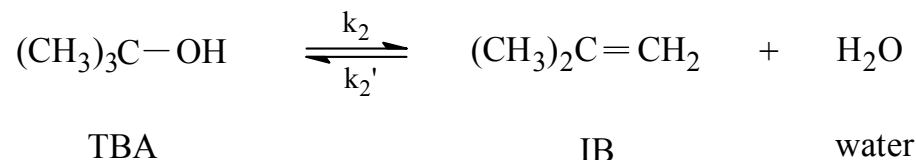

The third reaction which may take place, is the indirect formation of ETBE by ethanol and IB.

$\left(\mathrm{CH}_{3}\right)_{2} \mathrm{C}=\mathrm{CH}_{2}+\mathrm{CH}_{3}-\mathrm{CH}_{2}-\mathrm{OH} \stackrel{\mathrm{k}_{3}}{\rightleftharpoons} \underset{\mathrm{k}_{3}{ }^{\prime}}{\rightleftharpoons}\left(\mathrm{CH}_{3}\right)_{3} \mathrm{C}-\mathrm{O}-\mathrm{CH}_{2}-\mathrm{CH}_{3}$

IB

$\mathrm{EtOH}$

ETBE

The following mechanism was assumed for the ETBE synthesis: 


$$
\begin{aligned}
& \left(\mathrm{CH}_{3}\right)_{3} \mathrm{C}-\mathrm{OH}+\mathrm{R}-\mathrm{SO}_{3}-\mathrm{H} \rightleftharpoons\left(\mathrm{CH}_{3}\right)_{3} \mathrm{C}-\mathrm{O}^{+} \mathrm{H}_{2}+\mathrm{R}-\mathrm{SO}_{3}^{-} \\
& \left(\mathrm{CH}_{3}\right)_{3} \mathrm{C}-\mathrm{O}^{+} \mathrm{H}_{2}+\mathrm{CH}_{3}-\mathrm{CH}_{2}-\mathrm{OH} \rightleftharpoons\left(\mathrm{CH}_{3}\right)_{3} \mathrm{C}-\mathrm{O}-\mathrm{CH}_{2}-\mathrm{CH}_{3}+\mathrm{H}_{2} \mathrm{O}+\mathrm{H}^{+} \\
& \left(\mathrm{CH}_{3}\right)_{3} \mathrm{C}-\mathrm{O}^{+} \mathrm{H}_{2} \rightleftharpoons \mathrm{CH}_{2}=\mathrm{C}\left(\mathrm{CH}_{3}\right)_{2}+\mathrm{H}_{2} \mathrm{O}+\mathrm{H}^{+} \\
& \mathrm{R}-\mathrm{SO}_{3}^{-}+\mathrm{H}^{+} \rightleftharpoons \mathrm{R}-\mathrm{SO}_{3}-\mathrm{H}
\end{aligned}
$$

where $\mathrm{R}$ is the polymeric backbone of ion exchange resin catalyst.

In the first step, [equation (4)] TBA was converted to a solvated carbocation, a reactive unstable intermediate in the presence of strong acidic cation exchange resin catalyst. In the second step [equation (5)], the solvated carbocation combines with EtOH to form ETBE, water and hydrogen ion. The solvated carbocation could also be decomposed into IB, water and hydrogen ion [equation (6)]. The hydrogen ion $\left(\mathrm{H}^{+}\right)$ formed in reactions (5) and (6) helps the catalyst to regain its original matrix [see equation (7)]. Similar mechanism was proposed by Yao and Yang (2003) and Slomkiewicz (2004). The limiting step in this sequence of reactions is considered to be the surface reaction of ethanol and TBA adsorbed in the macropores of catalyst and TBA to yield ETBE. Under the experimental conditions (at atmospheric pressure) used in this work, IB was not detected in liquid phase even in very minute concentration and hence the backward reaction in equation (2) and the reaction mentioned in equation (3) can safely be neglected.

Rates of the reactions for equation (1) and equation (2) given by Kiatkittipong et al. (2000) can be written as:

$$
\begin{aligned}
& r_{1}=\frac{k_{1}\left(a_{A} a_{B}-\frac{a_{c} a_{D}}{K_{e q}}\right)}{1+K_{w} a_{D}} \\
& r_{2}=\frac{k_{2} a_{A}}{1+K_{w} a_{D}}
\end{aligned}
$$


where $k_{1}$ and $k_{2}$ are reaction rate constants for reactions (1) and (2); , $K_{w}$ is the water inhibition parameter; $K_{e q}$ is the equilibrium constant for activity based model and $a_{A}$, $a_{B}, a_{C}$ and $a_{D}$ are activity coefficients of TBA, EtOH, ETBA and water, respectively. The equilibrium constant was calculated from the following expression:

$$
K_{e q}=\left(\frac{a_{C} a_{D}}{a_{A} a_{B}}\right)_{e q}
$$

In this work, activities were used instead of concentrations to account for the nonideal behaviour of liquid phase reaction system. The activity of $i^{\text {th }}$ component was calculated by using the following equation:

$a_{i}=x_{i} \gamma_{i}$

where $x_{i}$ and $\gamma_{i}$ are mole fraction and activity coefficient of the $i^{\text {th }}$ component respectively. Activity coefficients were calculated by using the modified UNIFAC group contribution method (Gmehling et al., 1993; Skjold-Jǿgensen et al., 1979). The detailed calculation method is given by Kyle (2000).

To find out the expression for the rate constants and water inhibition parameter, experiments were carried out at three different temperatures i.e., $343 \mathrm{~K}, 348 \mathrm{~K}$, and $353 \mathrm{~K}$ respectively. After finding the values of $\mathrm{k}_{1}, \mathrm{k}_{2}$, and $\mathrm{K}_{\mathrm{w}}$, Arrhenius and van't Hoff plots were drawn and following equations were obtained for these constants.

$$
\begin{aligned}
& k_{1}=\exp \left(11.986-\frac{6212.5}{T}\right) \\
& k_{2}=\exp \left(14.861-\frac{7275.4}{T}\right) \\
& K_{W}=\exp \left(-30.82+\frac{11253}{T}\right)
\end{aligned}
$$

\section{Results and Discussion}




\section{Catalyst Characterization}

Different techniques used for catalysts characterisation are summarized below.

\section{Particle size distribution}

Coulter130 laser sizer was used to determine the size range of catalysts. The results are presented in terms of volume percentage versus size of particle in Figure 1. It can be seen from Figure 1 that most of the particles lie in the range of 425 and 850 microns for all catalysts. Another important feature of the ion exchange resin catalysts is the pore size distribution and incremental pore volume and Figure 2 shows how both of these parameters vary with respect to each other. This figure illustrates that all of these catalysts are macrporous, however more prominent access pores are observed for A-35 compared to A-15 and CT-145H. Data for other catalysts have already been published in our previous work (Teo and Saha, 2004; Saha et al., 2005).

BET surface area, Langmuir surface area, pore size and pore volume were measured by using Micromeritics ASAP2000 (Accelerated Surface Area and Porosimetry) instrument. It is to be mentioned that all catalysts were thermally dried and degassed but CT-124, due to its gelular matrix, did not exhibit any porosity with this method. So it was freeze dried with cyclohexane as solvent. But even after employing freeze drying technique we were unable to measure the porosity because the catalyst particles shrunk and the gelular matrix collapsed during the drying process and did not exhibit any porosity.

Scanning electron microscopy (SEM) was performed for all catalysts used in this study. Cambridge Stereoscan 360 was used at 15KV. Micrographs of few catalysts are shown in Figure 3 (a, b, c, d, and e). These micrographs suggest that there are pores of different sizes and geometry. Cracks of very minute size are also observed specially for CT-124 and CT-145H. Inside the resin beads show a cabbage like texture which 
suggests that pores are enmeshed together. The thin line cracks and macropores are responsible for the pore volume of the catalyst. The reactants may easily penetrate into these pores which act as substrate to ensure the chemical reaction.

\section{Density Measurement}

Bulk density was measured by filling the pre weighted known volume density bottle with catalyst and then mass of catalyst was found by difference and hence the density. True density was measured by using multivolume pycnometer-1305 with helium as an expansion medium. In both cases the measurements were replicated 5 in order to obtain reproducible results. The porosity was calculated by using equation (15).

$$
\varepsilon=\frac{\left(\rho_{\mathrm{T}}-\rho_{\mathrm{b}}\right) \times 100}{\rho_{\mathrm{T}}}
$$

where $\varepsilon$ is the porosity, $\rho_{\mathrm{T}}$ and $\rho_{\mathrm{b}}$ are true particle density and bulk particle density respectively. The physical properties and characterization results of catalysts are shown in Table 1.

\section{Elemental analysis}

Elemental analysis for all the catalysts was carried out in the Department of Pure and Applied Chemistry, University of Strathclyde, Glasgow, UK on a Perkin Elmer series II 2400 elemental analyser. Each sample was accurately weighed (1-2 mg) and wrapped in tin foil prior to analysis. The combustion of the sample was done in the combustion tube at $2073 \mathrm{~K}$ at a controlled environment in the presence of pure oxygen after purging the system with Helium carrier gas. The gaseous combustion products were further decomposed in the presence of a series of catalysts. A thermal conductivity detector quantified the percentage of carbon, hydrogen and nitrogen. The 
oxygen content was determined by difference. The results of elemental analysis are given in Table 2.

\section{Batch Kinetic Results}

Experiments were carried out to determine the best catalyst for ETBE synthesis at optimum conditions. To overcome the mass transfer resistance, agitation speed of 500 rpm was used after observation that there was no appreciable increase in conversion when the speed of agitation was increased up to $800 \mathrm{rpm}$. As higher impeller speed could cause attrition and disintegration of catalyst particles, impeller speed of $500 \mathrm{rpm}$ was considered optimum and maintained throughout this study.

\section{Effect of Ion Exchange Resin Catalysts}

All seven catalysts were tested under the same condition of temperature, feed mole ratio of reactants, stirrer speed and catalyst loading. TBA conversion and ETBE selectivity were determined for each catalyst which are shown in Figure 4. $\%$ Conversion of TBA and \%selectivity of ETBE were calculated from equation (16) and equation (17) respectively.

$\%$ Conversion of TBA $\left(\mathrm{X}_{\mathrm{A}}\right)=\frac{\left(\mathrm{C}_{T B A, 0}-\mathrm{C}_{T B A, t}\right)}{\mathrm{C}_{T B A, 0}} \mathrm{X} 100$

$\%$ Selectivity of ETBE $=\frac{\left(\mathrm{C}_{\mathrm{ETBE}, \mathrm{t}}\right)}{\left(\mathrm{C}_{\mathrm{TBA}, 0}-\mathrm{C}_{\mathrm{TBA}, \mathrm{t}}\right)} \mathrm{X} 100$

It was evident from Figure 4 that $\mathrm{CT}-124$ and $\mathrm{CT}-145 \mathrm{H}$ catalysts resulted in TBA conversion and ETBE selectivity in the range of $70 \%$ and $60 \%$ respectively. CT-175 and CT-275 catalyst yielded the maximum conversion but resulted in poor selectivity. Also, Amberlyst A-15 and A-35 as well as Purolite CT-151 resin catalysts were not found suitable from selectivity point of view for this etherification reaction. Though 
CT-124 and CT-145H catalyst gave similar results, CT-124 catalyst can be considered better because the selectivity towards ETBE remains stable for longer period of time. The higher catalytic activity of CT-124 compared to other catalysts can be attributed to the presence of gelular matrix in its structure that swells considerably in the presence of water. This may result in the significant increase in the catalytic activity of CT-124. Since the etherification reaction also produces water as a by-product, CT124 might have swollen enough which might have increased its catalytic activity. CT-124 catalyst was therefore used extensively for all subsequent reactions.

\section{Effect of Temperature}

Experiments were carried out at $343 \mathrm{~K}, 348 \mathrm{~K}$ and $353 \mathrm{~K}$ to find the effect of temperature on TBA conversion and selectivity towards ETBE using CT-124 catalyst. Results are shown in Figure 5. Figure 5 confirms that temperature $343 \mathrm{~K}$ gave the best conversion and selectivity. The maximum value of selectivity was approximately equal for all three temperatures but it became consistent after four hours for experiment that was carried out at $343 \mathrm{~K}$ while the selectivity decreases with time for other two temperatures. The reason for decrease in ETBE selectivity at higher temperature can be attributed to the formation of IB during the course of reaction. Similar behaviour was noticed for other catalysts at higher temperatures. As a result, $343 \mathrm{~K}$ was considered to be the optimum temperature for this reaction in the presence of CT-124 catalyst.

\section{Effect of Feed Mole Ratio}

The effect of feed mole ratios (EtOH to TBA) on TBA conversion and ETBE selectivity was investigated. The results are shown in Figure 6. It can be seen from 
Figure 6 that feed mole ratio of 2:1 of EtOH:TBA produced higher conversion and better selectivity towards ETBE compared to feed mole ratio of 1:1. Therefore 2:1 feed mole ratio was considered optimum for this study.

\section{Effect of Catalyst Loading}

To investigate the effect of the amount of catalyst added to the reaction system on TBA conversion and ETBE selectivity, experiments were carried out using two different catalyst loadings, e.g., 2.5\% (w/w) and 5.0\% (w/w). Figure 7 shows how conversion and selectivity varies with the increase in the amount of catalyst from $2.5 \%(\mathrm{w} / \mathrm{w})$ to $5.0 \%(\mathrm{w} / \mathrm{w})$. It was observed that catalyst loading of $2.5 \%(\mathrm{w} / \mathrm{w})$ yielded reasonably good selectivity but gave lower conversion compared to $5.0 \%$ $(\mathrm{w} / \mathrm{w})$ catalyst loading. The $5.0 \%(\mathrm{w} / \mathrm{w})$ and $10.0 \%(\mathrm{w} / \mathrm{w})$ loading produced very similar results in terms of conversion of TBA and selectivity towards ETBE. Since doubling the amount of catalyst did not yield appreciable benefit in terms of conversion and selectivity, $5.0 \%(\mathrm{w} / \mathrm{w})$ catalyst loading was considered suitable and was used in most of the experiments for this etherification study.

\section{Kinetic Modelling}

The heterogeneous catalytic reaction models namely Langmuir-HinshelwoodHougen-Watson (LHHW) and Eley-Riedel (ER) models were applied to fit the experimental data. Reaction rate expression for LHHW and ER models can be expressed as follows:

LHHW model

$$
-r_{A}=\frac{A_{f}\left(\frac{-E_{0}}{R T}\right)\left(a_{A} a_{B}-\frac{A_{r}}{A_{f}} a_{C} a_{D}\right)}{\left(1+K_{A} a_{A}+K_{B} a_{B}+K_{C} a_{C}+K_{D} a_{D}\right)^{2}}
$$


ER model

$$
-r_{A}=\frac{A_{f}\left(\frac{-E_{0}}{R T}\right)\left(a_{A} a_{B}-\frac{A_{r}}{A_{f}} a_{C} a_{D}\right)}{\left(1+K_{A} a_{A}+K_{B} a_{B}+K_{C} a_{C}+K_{D} a_{D}\right)^{2}}
$$

The expression for the two models in terms of equilibrium constant reduces to the following forms:

\section{LHHW}

$$
-r_{A}=\frac{k_{1}\left(a_{A} a_{B}-\frac{a_{C} a_{D}}{K_{e q}}\right)}{\left(1+K_{A} a_{A}+K_{B} a_{B}+K_{C} a_{C}+K_{D} a_{D}\right)^{2}}
$$

ER model

$$
-r_{A}=\frac{k_{1}\left(a_{A} a_{B}-\frac{a_{C} a_{D}}{K_{e q}}\right)}{\left(1+K_{A} a_{A}+K_{B} a_{B}+K_{C} a_{C}+K_{D} a_{D}\right)}
$$

When all the experimental values were incorporated into LHHW and ER model equations represented by equation (20) and equation (21), both the models gave negative values of adsorption coefficients. Similar negative values of adsorption coefficients were reported by other researchers (Fite et al., 1994; Yin et al., 1995). Multiple linear and non linear regression techniques were used to calculate the constants of equations (19) and (20) [Cutlip and Shacham, 1999]. Both the models were found to be non-coherent and inconsistent.

It was observed that during the experiments water was formed more rapidly than ETBE which is understandable because it is formed in both reactions (1) and (2) and also the reaction rates values were very small. This can be explained as the polar 
molecules like ethanol and water are preferentially adsorbed on the catalyst surface, decreasing the number of active sites available for reaction towards the formation of desired product.

Since both the heterogeneous models were unable to predict the experimental data, Quasi-homogeneous $(\mathrm{QH})$ model was used to interpret the experimental batch kinetic data. QH model is applicable for highly polar reaction medium. In the present work, QH model is used considering Helfferich (1962) concept which considers that catalysis of liquid phase reactions using ion-exchange resins is similar to homogeneous catalysis by dissolved electrolytes. A numerous authors have modelled the heterogeneous kinetic data using QH model [Chopade and Sharma (1997); Saha (1999); Jiménez et al. (2002); Gangadwala et al. (2003); Steinigeweg and Gmehling (2004) and Schmitt and Hasse (2006)].

Reaction rate equation for the $\mathrm{QH}$ model in general form and in terms of equilibrium constant are as follows:

$$
\begin{aligned}
& -r_{A}=A_{f}\left(\frac{-E_{0}}{R T}\right)\left(a_{A} a_{B}-\frac{A_{r}}{A_{f}} a_{c} a_{D}\right) \\
& -r_{A}=k_{1}\left(a_{A} a_{B}-\frac{a_{c} a_{D}}{K_{e q}}\right)
\end{aligned}
$$

The QH model fitted the experimental data very well when compared with other heterogeneous rate models (e.g. LHHW and ER models) as the latter gave negative values of adsorption coefficients (Fite et al., 1994; Yin et al., 1995). Experimental and QH model values are shown in Figure 5 (d) and Figure 8 respectively. Both these figures show that $\mathrm{QH}$ model describes the system more adequately than the heterogeneous reaction models. Even though the system is heterogeneous, it can be assumed that contents of reaction vessel are so intimately mixed that it almost 
approaches to homogeneous system. Expression for rate constant $k_{1}$ for this system was found by using Arrhenius equation which is given by equation (24):

$k_{1}=\exp \left(11.827-\frac{6429.6}{T}\right)$

The Arrhenius plot was drawn from equation (24) using three different temperatures that was used in the present work and is given in Figure 9. The calculated values of Arrhenius coefficient and activation energy are $1.8 \times 10^{5}$ and $53.455 \mathrm{KJ} / \mathrm{mol}$, respectively. These values are in agreement with the published literature (Yang et al., 2000).

\section{Conclusions}

Liquid phase etherification of two alcohols, namely TBA and EtOH to synthesize ETBE was carried out in the presence of gelular and macroporous ion exchange resin catalysts. Among the various catalysts used CT-124 (gelular matrix) and CT-145H (macroporous) were found to perform better than other catalysts for this etherification reaction. Among these two catalysts studied, CT-124 produced better results than CT$145 \mathrm{H}$ as selectivity towards ETBE decreased after few hours of reaction in case of CT-145H. Feed mole ratio of 2:1 (EtOH:TBA) and catalyst loading of 5.0\% (w/w) were found to be optimum for this system. Heterogeneous kinetic models e.g., LHHW and ER did not predict the experimental results appropriately. However, the experimental data were fitted very well by applying the Quasi-homogeneous $(\mathrm{QH})$ model. Kinetic studies for ETBE synthesis in the batch reactor would be helpful for ETBE synthesis in a reactive distillation column.

\section{Acknowledgements}


One of the authors (MU) is grateful to the Higher Education Commission (HEC),

Pakistan for funding this research under International Research Support Initiative programme that helped him to conduct the research at Loughborough University, UK. The support of Dr. Krzysztof Ambroziak and other laboratory staff at Loughborough University is gratefully acknowledged. The authors wish to thank Purolite International Limited, especially Dr. Jim Dale, for kindly supplying the catalysts.

\section{Notations}

$A_{f} \quad$ Arrhenius coefficient for forward reaction

$A_{r} \quad$ Arrhenius coefficient for backward reaction

$a_{i} \quad$ activity of $i^{\text {th }}$ component

C concentration of component

$\left[\mathrm{Kmol} / \mathrm{m}^{3}\right]$

$k_{1} \quad$ rate constant of reaction 1 for activity based model

$\left[\mathrm{Kmol} / \mathrm{m}^{3} \cdot \mathrm{s}\right]$

$k_{2} \quad$ rate constant of reaction 2 for activity based model

$\left[\mathrm{Kmol} / \mathrm{m}^{3} \cdot \mathrm{s}\right]$

$K \quad$ adsorption constant

$[-]$

$K_{e q} \quad$ equilibrium constant for reaction in activity based model

$K_{w} \quad$ water inhibition parameter for activity based model

$\left[\mathrm{mol}^{6} / \mathrm{m}^{2}\right]$

$r \quad$ reaction rate

$\left[\mathrm{Kmol} / \mathrm{m}^{3} \cdot \mathrm{s}\right]$

$T$ temperature

$x_{i} \quad$ mole fraction of $i^{\text {th }}$ component in liquid mixture

\section{Subscripts}

$0 \quad$ at time $\mathrm{t}=0$

1 for reaction 1 
2 for reaction 2

$A \quad$ TBA

$B \quad \mathrm{EtOH}$

$b \quad$ bulk particle

C ETBE

D water

$e q \quad$ at equilibrium

$i \quad$ for $i^{\text {th }}$ component

$\mathrm{T}$ true particle

$t \quad$ at any instant of time $\mathrm{t}$

\section{Abbreviations}

EtOH ethyl alcohol

ETBE ethyl tert-butyl ether

$\mathrm{H}_{2} \mathrm{O} \quad$ water

IB iso-butylene

TBA tert-butyl alcohol

LHHW Langmuir-Hinshelwood-Hougen-Watson

ER Eley-Rideal

QH Quasi-homogeneous

tert tertiary

\section{Greek letters}
$\varepsilon$
Particle porosity
$[-]$
$\rho \quad$ Particle density
$\left[\mathrm{Kg} / \mathrm{m}^{3}\right]$ 


\section{References}

Assabumrangrat, S., Kiatkittipong, W., Srivitoon, N., Praserthdam, P., Goto, S., (2002). Kinetics of liquid phase synthesis of ethyl tert-butyl ether from tert-butyl alcohol and ethanol catalyzed by supported $\beta$-Zeolite. International Journal of Chemical Kinetics, 34, 292-297.

Assabumrangrat, S., Wongwattanasate, D., Pavarajarn, V., Praserthdam, P., Arpornwichanop, A., Goto, S., (2004). Production of ethyl tert-butyl ether from tertbutyl alcohol and ethanol catalyzed by $\beta$-Zeolite in reactive distillation. Korean Journal of Chemical Engineering, 21 (6), 1139-1146.

Bisowarno, B. H., Tade, M.O., (2000). Dynamic simulation of start up in ethyl tertbutyl ether reactive distillation with input multiplicity. Industrial and Engineering Chemistry Research, 39, 1950-1954.

Chopade, S. P.; Sharma, M. M. (1997). Reaction of ethanol and formaldehyde: Use of versatile cation-exchange resins as catalyst in batch reactors and reactive distillation columns. Reactive and Functional Polymers, 32, 53-64.

Cutlip, M. B., Shacham, M., (1999). Problem solving in chemical engineering with numerical methods. Prentice Hall International Series, 77, 357. 
Fite, C., Iborra, M., Tejero, J., Izquierdo, J., Cunnil, F., (1994). Kinetics of the liquid phase synthesis of ethyl tert-butyl ether. Industrial and Engineering Chemistry Research, 33, 581-591.

Gangadwala, J.; Mankar, S.; Mahajani, S., (2003). Esterification of acetic acid with butanol in the presence of ion-exchange resins as catalysts. Industrial and Engineering Chemistry Research, 42, 2146-2155.

Gmehling, J., Li, J. Schiller, M., (1993). A modified UNIFAC model 2. present parameter matrix and results for different thermodynamic properties. Industrial and Engineering Chemistry Research, 32, 178-193.

Helfferich, F. Ion Exchange. McGraw-Hill, New York, NY, 1962.

Jiménez, L.; Garvín, A.; Costa-López, J., (2002). The production of butyl acetate and methanol via reactive and extractive distillation. I. Chemical Equilibrium, Kinetics, and Mass-Transfer Issues. Industrial and Engineering Chemistry Research, 41, 66636669.

Kiatkittipong, W., Assabumrungrat, P., Praserthdam, P., Goto, S., (2002). A pervaporation membrane reactor for liquid phase synthesis of ethyl tert-butyl ether from tert-butyl alcohol and ethanol. Journal of Chemical Engineering Japan, 35 (6), $547-556$. 
Kyle, B.G., (2000). Chemical and Process Thermodynamics, $3^{\text {rd }}$ Ed. Prentice Hall PTR, 270.

Matouq, M., Tagawa, T., Goto, S., (1993). Liquid phase synthesis of methyl tert-butyl ether on heterogeneous heteropoly acid catalyst. Journal of Chemical Engineering Japan, 26, 254-258.

Matouq, M., Quitain, A., Takahashi, K., Goto, S., (1996). Reactive distillation for synthesizing ethyl tert-butyl ether from low grade alcohol catalyzed by potassium hydrogen sulphate. Industrial and Engineering Chemistry Research, 35, 982-986.

Quitain, A., Itoh, H., Goto, S., (1999). Reactive distillation for synthesizing ethyl tertbutyl ether from bio ethanol. Journal of Chemical Engineering Japan, 32, 280-287.

Saha, B, (1999). Ion-exchange resin catalysed etherification of dicyclopentadiene (DCPD) with methanol. Reactive and Functional Polymers, 40, 51-60.

Saha, B., Teo, H. T. R., Alqahtani, A., (2005). Iso-amyl acetate synthesis by catalytic distillation. International Journal of Chemical Reactor Engineering, 3, 1-16.

Schmitt, M.; Hasse, H., (2006). Chemical equilibrium and reaction kinetics of heterogeneously catalyzed $n$-hexyl acetate esterification. Industrial and Engineering Chemistry Research, 45 (12), 4123-4132. 
Skjold-Jǿgensen, S., Kolbe, B., Gmehling, J., Rasmussen, P., (1979). Vapour-liquid equilibria by UNIFAC group contribution, revision and extension. Industrial Engineering Chemistry Process Design and Development, 18 (4), 714-722.

Skjold-Jǿgensen, S., Rasmussen, P., Fredenslund, A., (1982). On concentration dependence of UNIQUAC/UNIFAC models. Chemical Engineering Science, 37 (1), 99-111.

Slomkiewicz, P. M., (2004). Determination of the Langmuir-Hinshelwood Kinetic Equation of Synthesis of Ethers. Applied Catalysis A: General, 269 (1-2), 33-42.

Sneesby, M. G., Tade, M. O., Datta, R., Smith, T. N., (1997). ETBE synthesis via reactive distillation 1. Steady-state simulation and design aspects. Industrial and Engineering Chemistry Research, 36, 1855-1869.

Sneesby, M. G., Tade, M. O., Datta, R., Smith, T. N., (1997). ETBE synthesis via reactive distillation 2. Dynamic simulation and control aspects. Industrial and Engineering Chemistry Research, 36, 1870-1881.

Steinigeweg, S.; Gmehling, J., (2004). Transesterification Processes by Combination of Reactive Distillation and Pervaporation. Chem. Eng. Process. 43, 447-456.

Teo, H.T.R. and Saha, B., (2004). Heterogeneous catalysed esterification of acetic acid with iso-amyl alcohol: kinetic studies, Journal of Catalysis, 228(1), 174-182. 
Yang, B., Yang, S., Yao, R., (2000). Synthesis of ethyl tert-butyl ether from tert-butyl alcohol and ethanol on strong acid cation-exchange resins. Reactive and Functional Polymers, 44, 167-175.

Yao R., Yang B. (2003). Study on the reaction rate and mechanism of synthesis of tert-butyl ethyl ether in liquid phase based on synergetics. Chemistry Journal on Internet, $5(11), 85$.

Yin, X., Yang, B., Goto, S., (1995). Kinetics of liquid phase synthesis of ethyl tertbutyl ether from tert-butyl alcohol and ethanol catalyzed by ion exchange resin and hetero poly acid. International Journal of Chemical Kinetics, 27, 1065-1074. 


\section{List of Tables}

Table 1. Physical properties and Characterization results of various catalysts.

Table 2. Elemental analysis of ion exchange catalyst resins. 
Table 1. Physical Properties of Catalysts and Characterization Results.

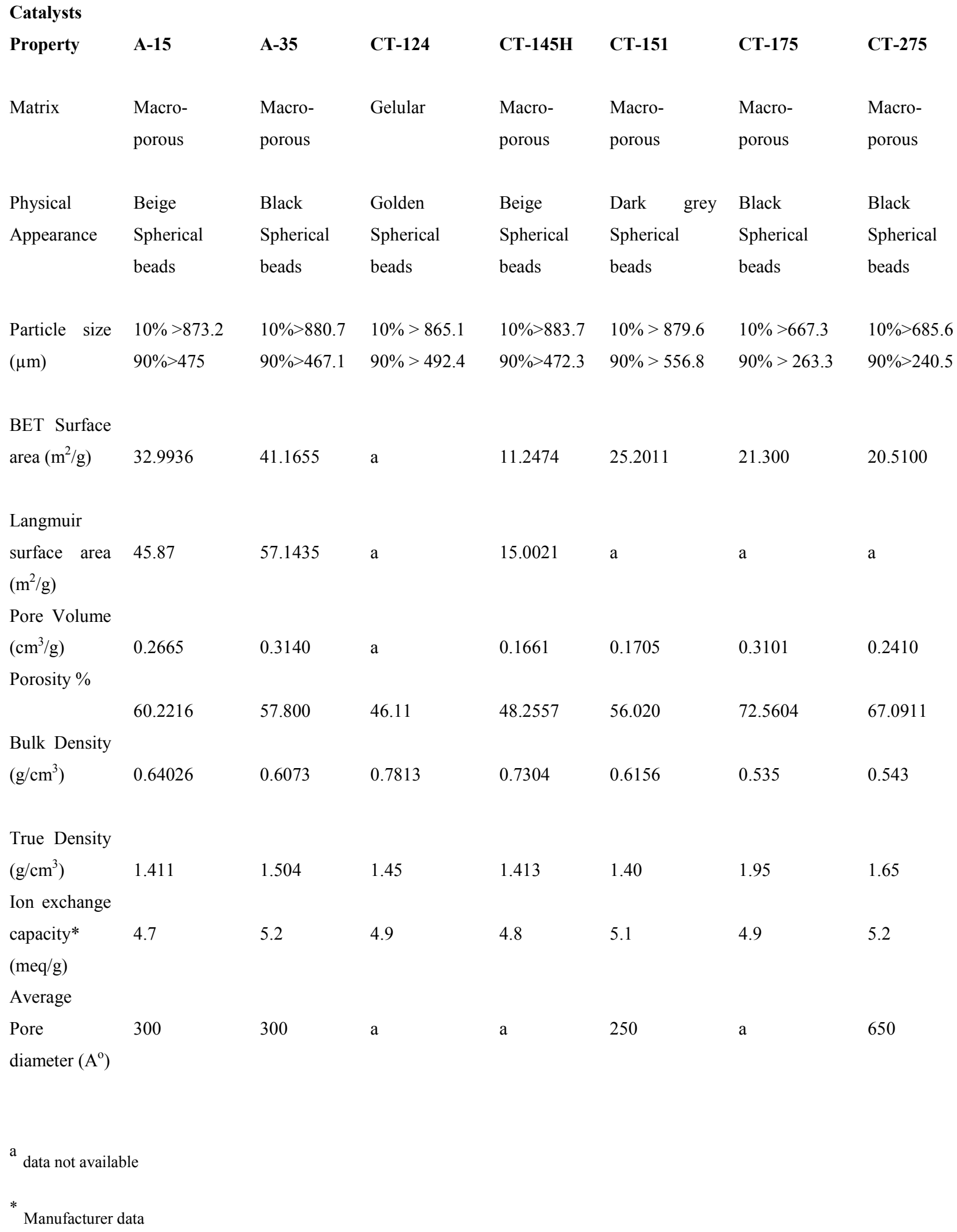


Table 2. Elemental analysis results of the catalysts used.

\begin{tabular}{lcccc}
\multicolumn{1}{c}{ Catalyst } & \% C & \% H & \% S & \% O* \\
Amberlyst-15 & 35.0 & 4.30 & 12.13 & 48.57 \\
Amberlyst-35 & 31.80 & 5.50 & 12.71 & 49.99 \\
CT-124 & 35.30 & 4.30 & 13.71 & 46.69 \\
CT-145H & 43.30 & 5.30 & 13.90 & 37.50 \\
CT-151 & 40.40 & 5.10 & 13.75 & 41.75 \\
CT-175 & 44.57 & 5.64 & 15.05 & 34.74 \\
CT-275 & 49.85 & 4.46 & 17.53 & 28.17
\end{tabular}

* Oxygen by difference. 


\section{List of Figures}

Figure 1. Particle size distribution of ion exchange resin catalysts.

Figure 2. Incremental pore volume vs pore width using BET method.

Figure 3. (a) SEM image of CT-124; (b) SEM of Internal structure of CT-145H; (c) Amberlyst-15 micrograph; (d) Internal pore structure of CT-151; (e) Surface structure of Amberlyst-35.

Figure 4. Effect of catalyst on (a) conversion of TBA and (b) selectivity of ETBE at temperature: $343 \mathrm{~K}$; catalyst loading: $5.0 \%(\mathrm{w} / \mathrm{w})$; feed mole ratio (EtOH to TBA): 2 : 1; stirrer speed: $500 \mathrm{rpm}$.

Figure 5. Conversion of TBA and selectivity of ETBE at (a) temperature: $343 \mathrm{~K}$, (b) temperature: $348 \mathrm{~K}$ and (c) temperature: $353 \mathrm{~K}$; and (d) comparison of experimental and calculated values (QH model) for TBA conversion at $343 \mathrm{~K}, 348 \mathrm{~K}$ and $353 \mathrm{~K}$ for catalyst loading: $5.0 \%(\mathrm{w} / \mathrm{w})$; feed mole ratio (EtOH to TBA): $2: 1$; catalyst: CT-124; stirrer speed: $500 \mathrm{rpm}$.

Figure 6. Effect of feed mole ratio (EtOH to TBA) on (a) conversion of TBA and (b) selectivity of ETBE at temperature: $343 \mathrm{~K}$; catalyst loading: $5.0 \%(\mathrm{w} / \mathrm{w})$; catalyst: CT-124; stirrer speed: 500 rpm.

Figure 7. Effect of catalyst loading on (a) conversion of TBA and (b) selectivity of ETBE at temperature: $343 \mathrm{~K}$; feed mole ratio (EtOH to TBA): 2 : 1; catalyst: CT-124; stirrer speed: $500 \mathrm{rpm}$.

Figure 8. Concentration profile for experimental and calculated values (QH model) at temperature: (a) $343 \mathrm{~K}$, (b) 348 and (c) $353 \mathrm{~K}$; catalyst loading: 5.0\% (w/w); feed mole ratio (EtOH to TBA): 2 : 1; catalyst: CT-124; stirrer speed: $500 \mathrm{rpm}$.

Figure 9. Arrhenius plot for ETBE synthesis. 


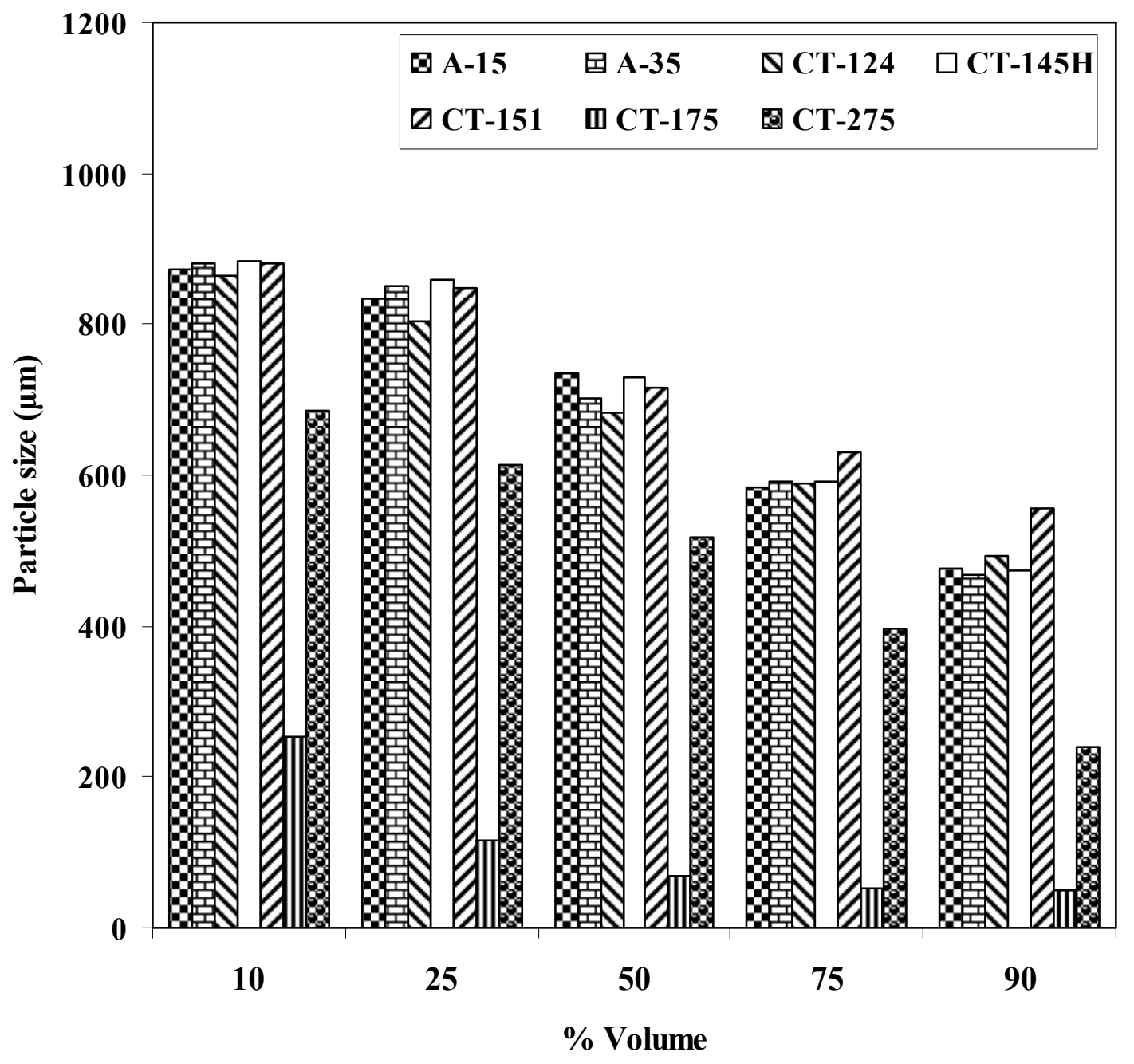

Figure 1. Particle size distribution of ion exchange resin catalysts. 


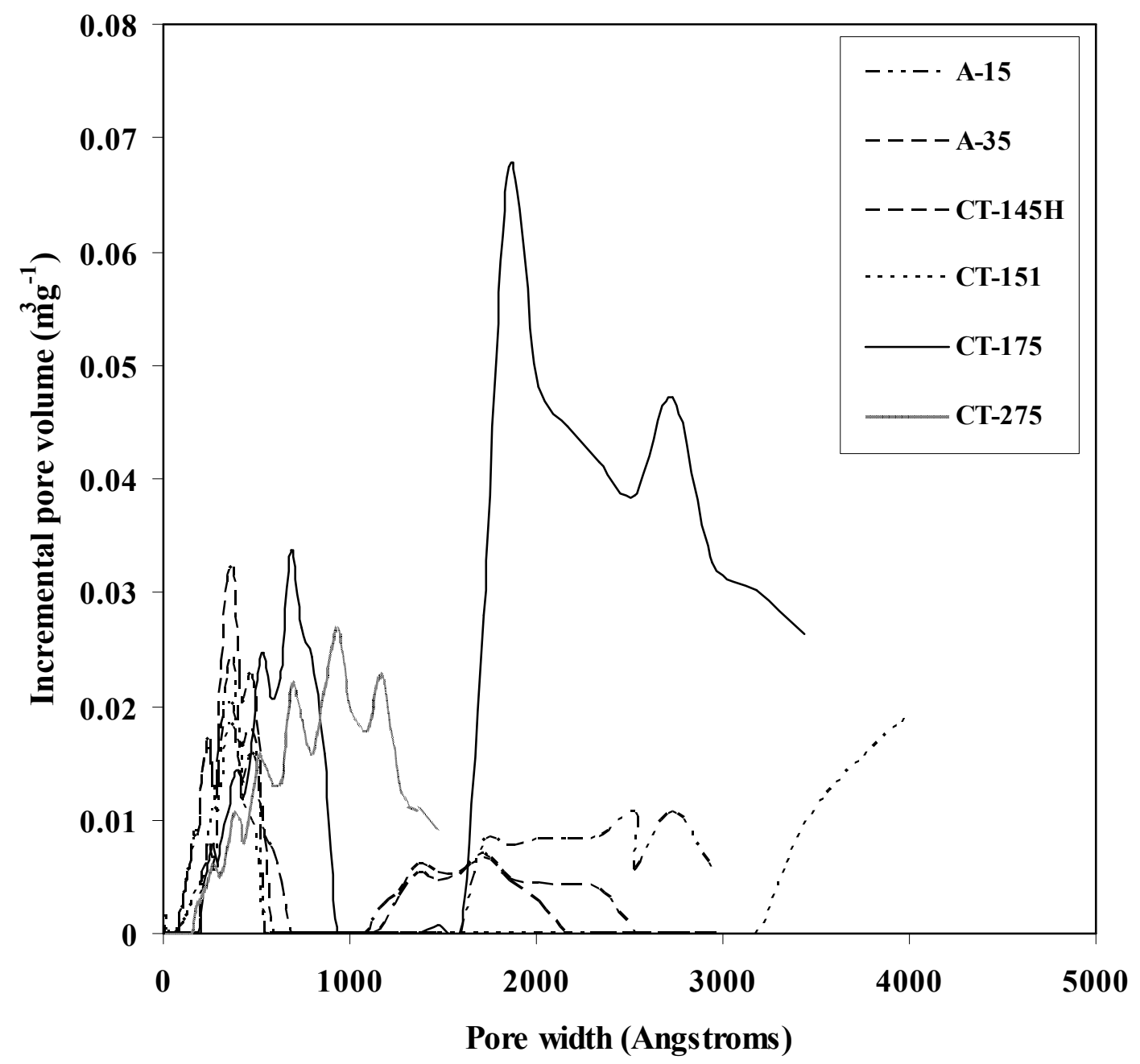

Figure 2. Incremental pore volume vs pore width using BET method. 


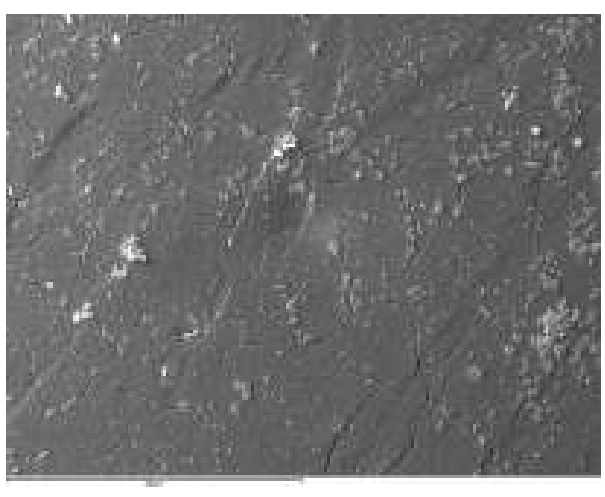

(a)

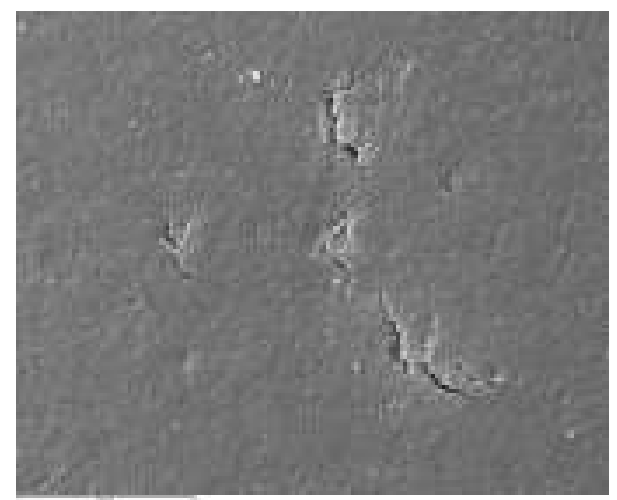

(c)

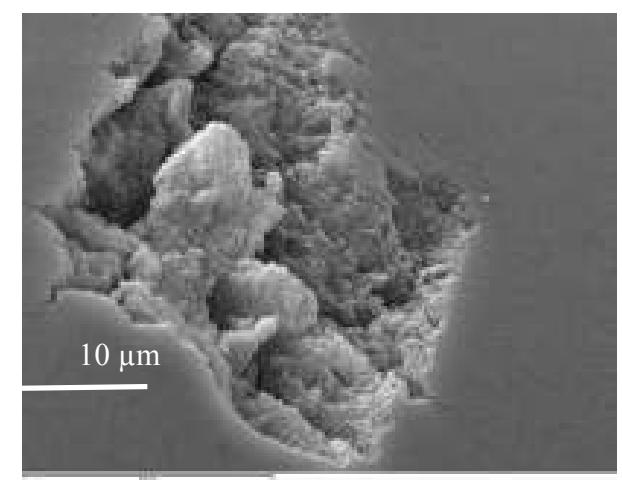

(b)

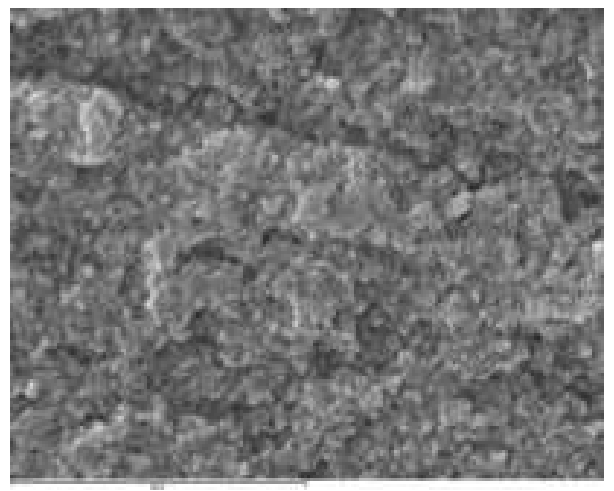

(d)

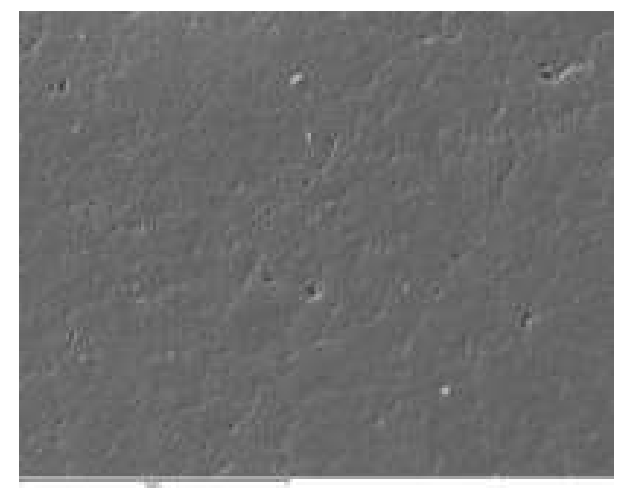

(e)

Figure 3. Scanning electron micrographs (SEMs) of different catalysts. (a) image of CT-124 catalyst surface; (b) internal structure of CT-145H; (c) image of Amberlyst15 catalyst surface; (d) internal pore structure of CT-151; (e) image of Amberlyst-35 catalyst surface. 


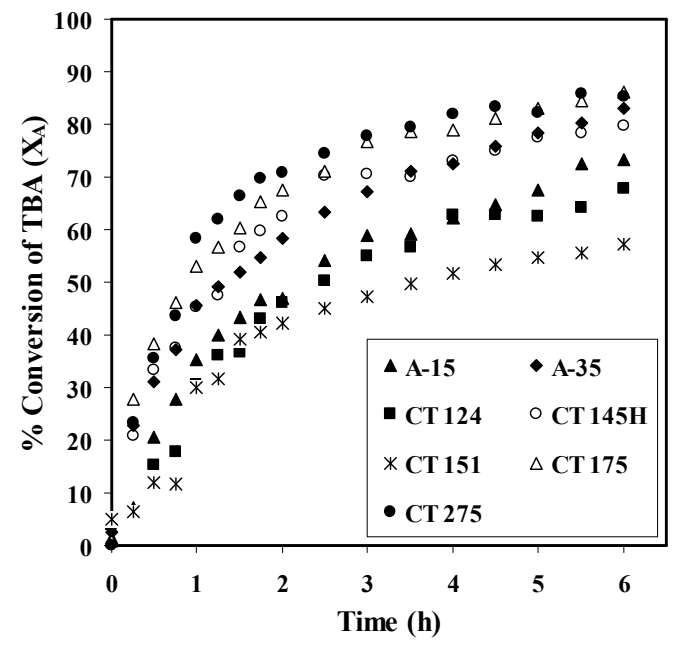

(a)

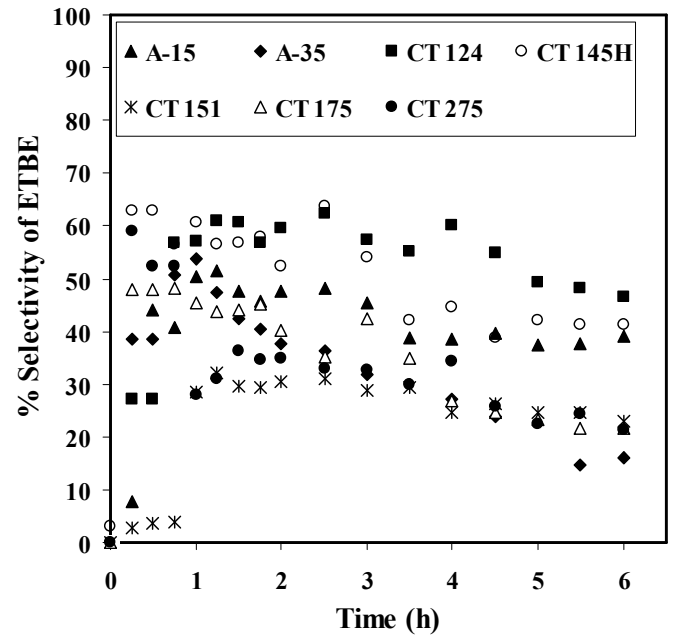

(b)

Figure 4. Effect of catalyst on (a) conversion of TBA and (b) selectivity of ETBE at temperature: $343 \mathrm{~K}$; catalyst loading: $5.0 \%(\mathrm{w} / \mathrm{w})$; feed mole ratio (EtOH to TBA): 2:1; stirrer speed: $500 \mathrm{rpm}$. 


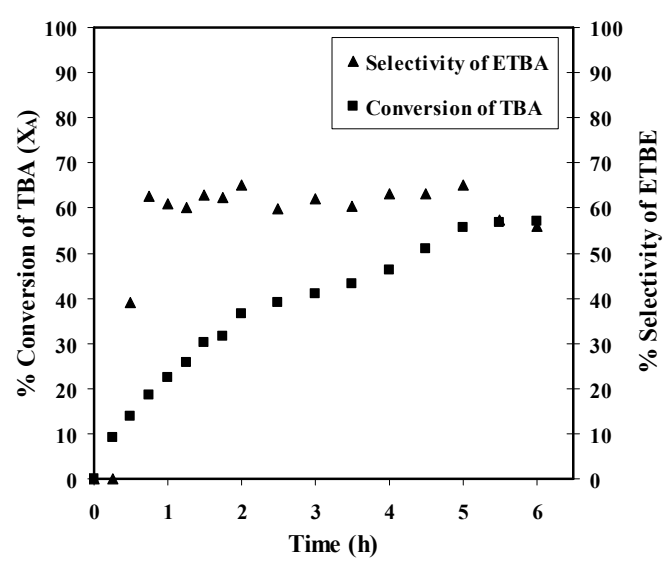

(a)

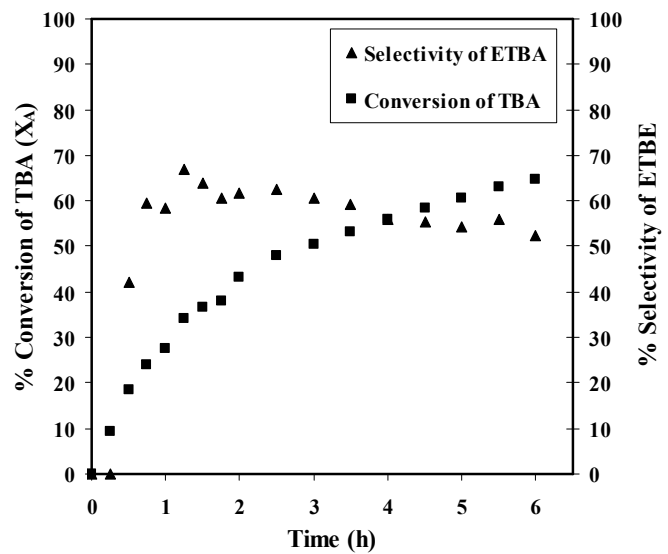

(c)

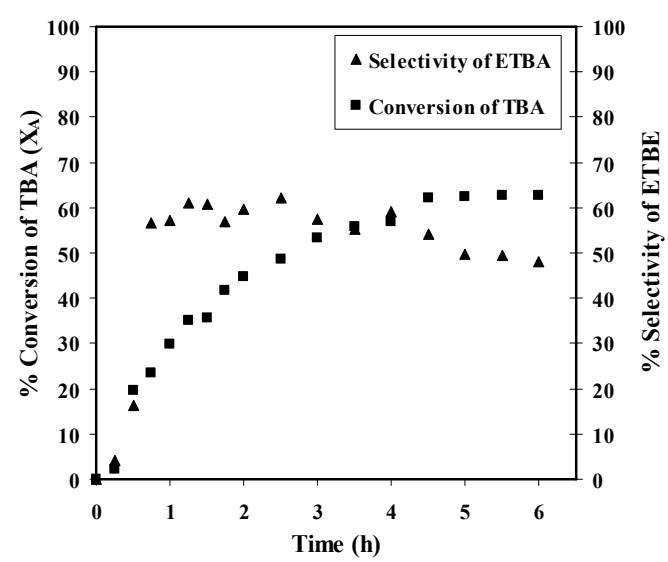

(b)

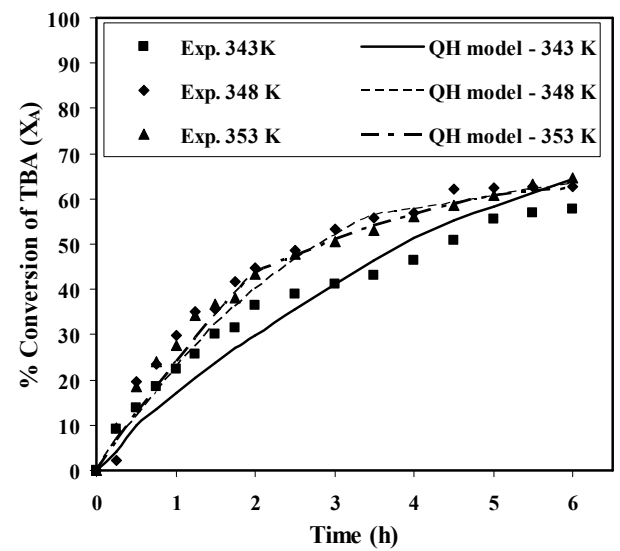

(d)

Figure 5. Conversion of TBA and selectivity of ETBE at (a) temperature: $343 \mathrm{~K}$, (b) temperature: $348 \mathrm{~K}$ and (c) temperature: $353 \mathrm{~K}$; and (d) comparison of experimental and calculated values (QH model) for TBA conversion at $343 \mathrm{~K}, 348 \mathrm{~K}$ and $353 \mathrm{~K}$ for catalyst loading: $5.0 \%(\mathrm{w} / \mathrm{w})$; feed mole ratio (EtOH to TBA): $2: 1$; catalyst: $\mathrm{CT}-124$; stirrer speed: $500 \mathrm{rpm}$. 


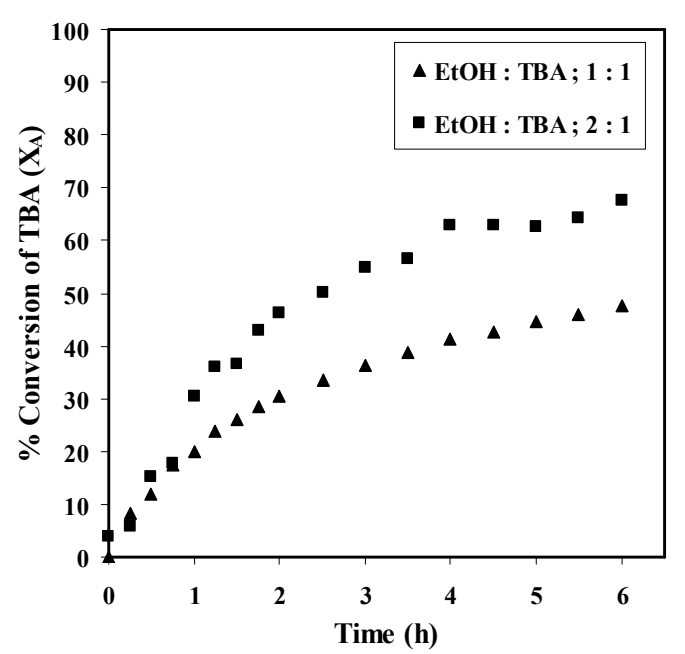

(a)

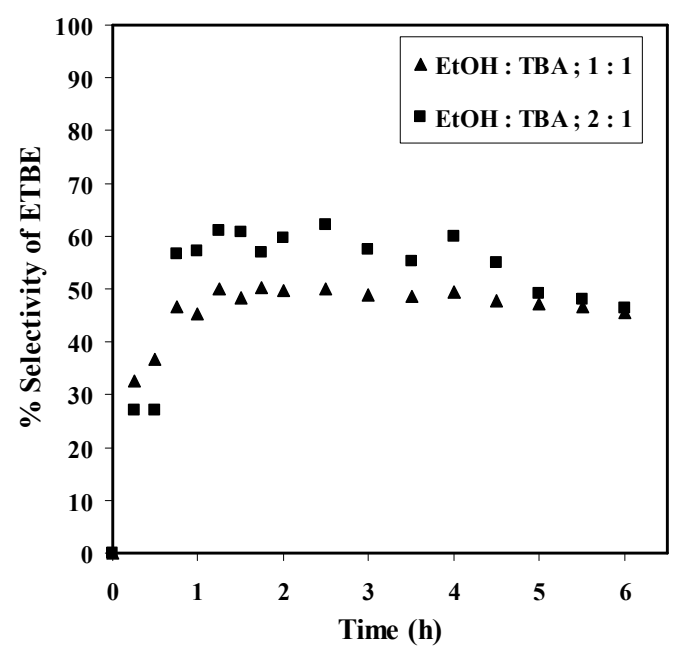

(b)

Figure 6. Effect of feed mole ratio (EtOH to TBA) on (a) conversion of TBA and (b) selectivity of ETBE at temperature: $343 \mathrm{~K}$; catalyst loading: $5.0 \%(\mathrm{w} / \mathrm{w})$; catalyst: CT-124; stirrer speed: 500 rpm. 


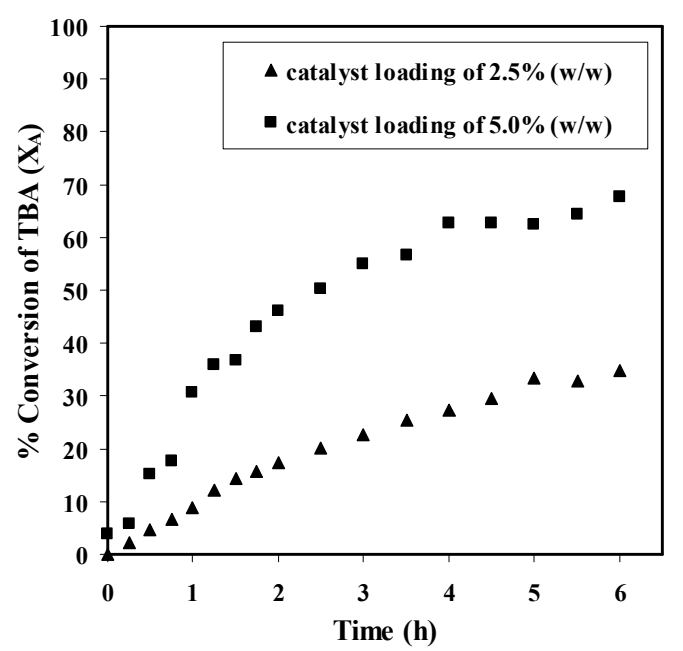

(a)

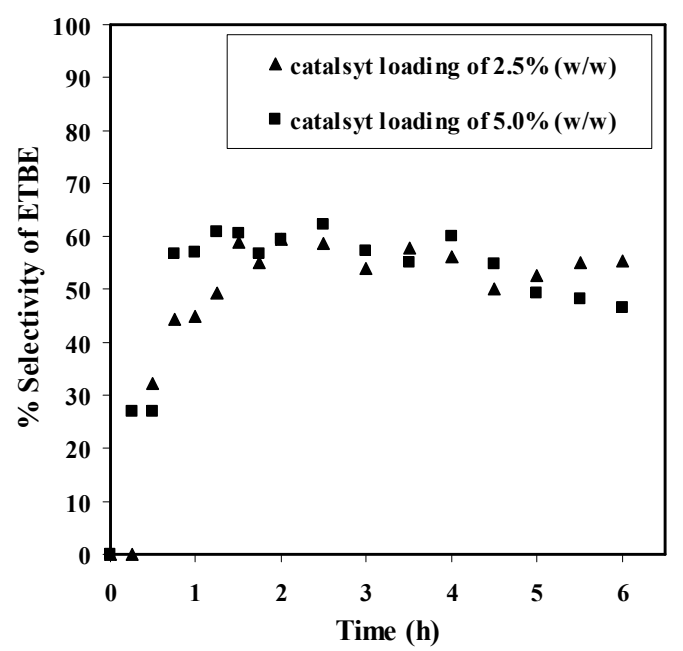

(b)

Figure 7. Effect of catalyst loading on (a) conversion of TBA and (b) selectivity of ETBE at temperature: $343 \mathrm{~K}$; feed mole ratio (EtOH to TBA): 2:1; catalyst: CT-124; stirrer speed: $500 \mathrm{rpm}$. 


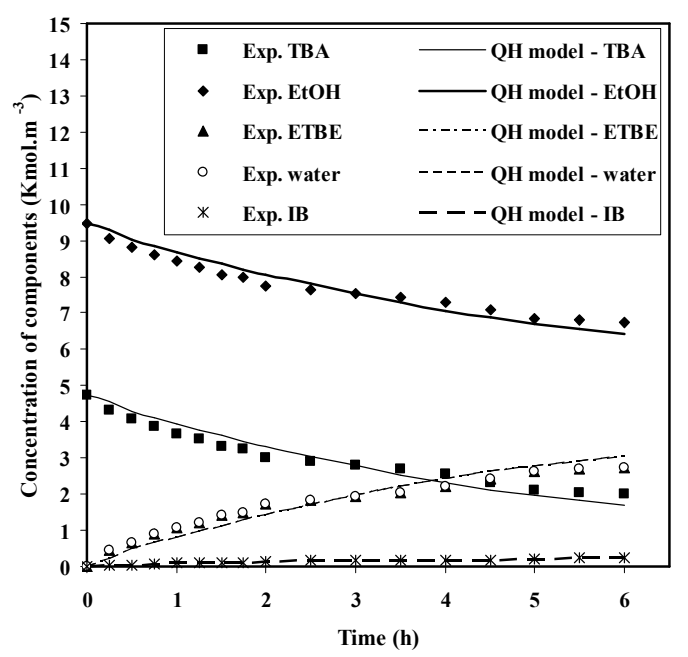

(a)

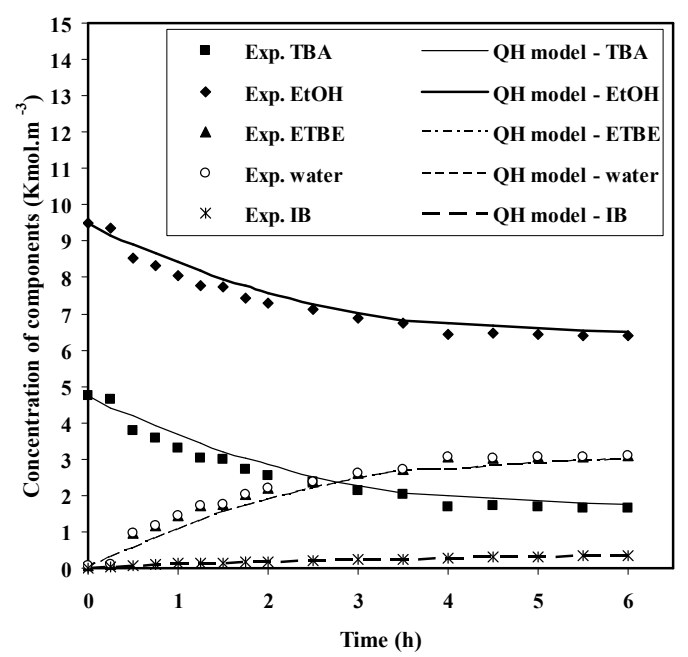

(b)

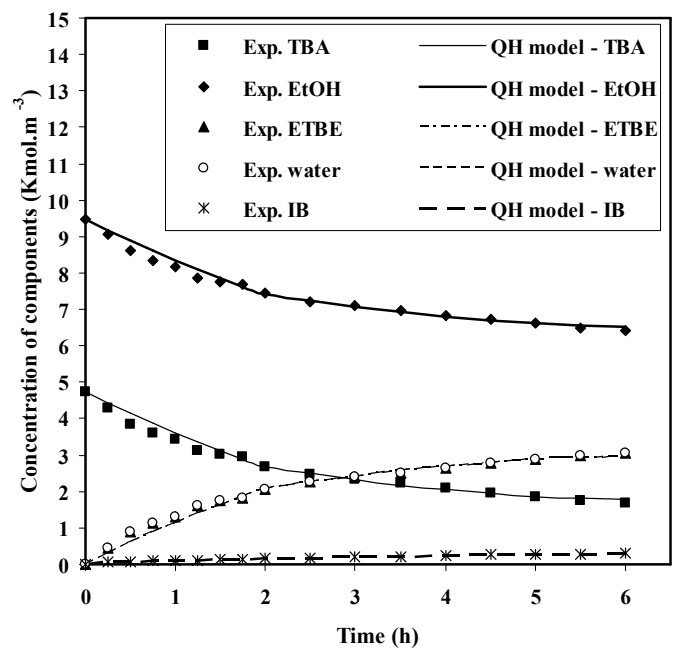

(c)

Figure 8. Concentration profile for experimental and calculated values $(\mathrm{QH}$ model $)$ at temperature: (a) $343 \mathrm{~K}$, (b) 348 and (c) $353 \mathrm{~K}$; catalyst loading: 5.0\% (w/w); feed mole ratio (EtOH to TBA): 2 : 1; catalyst: CT-124; stirrer speed: 500 rpm. 
Page 35

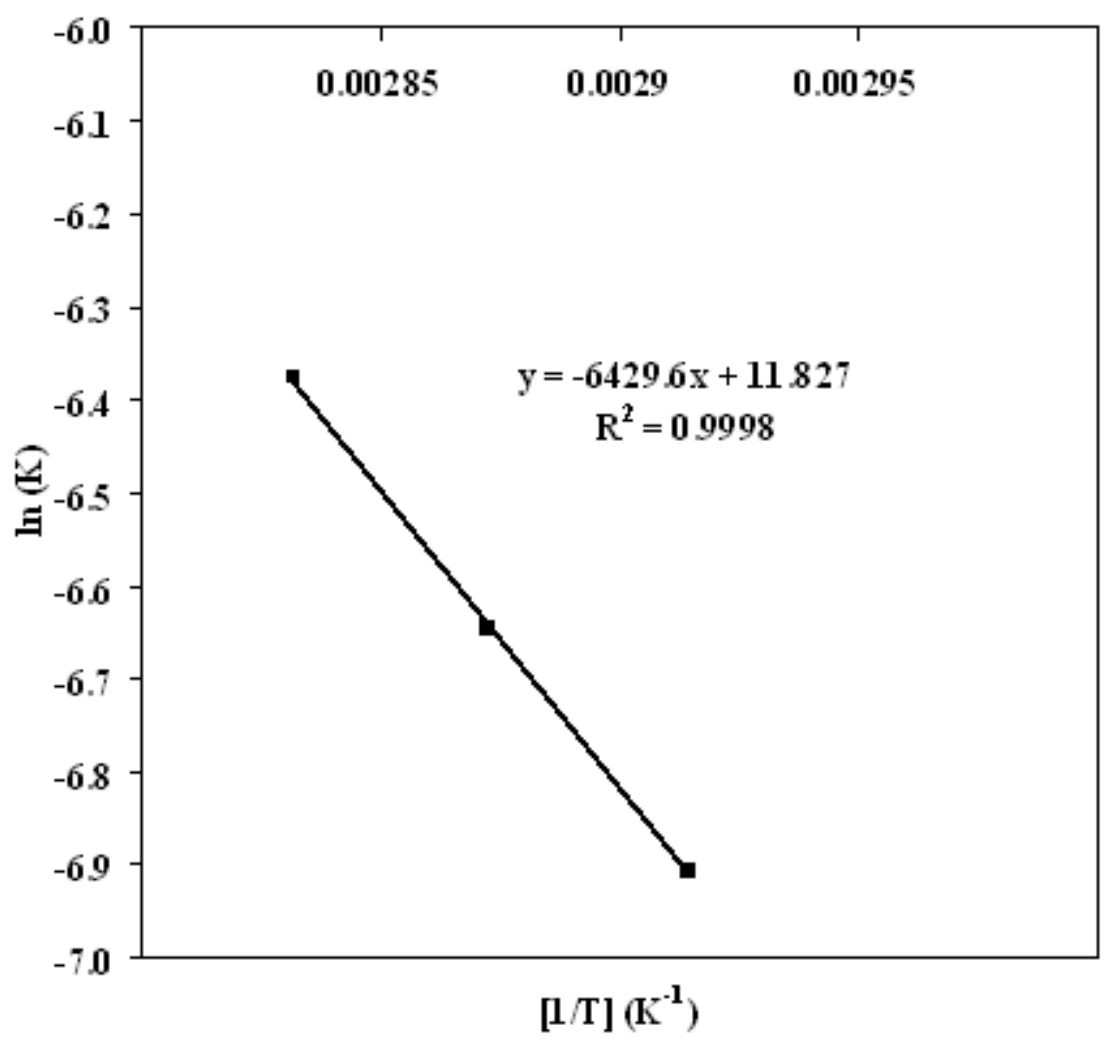

Figure 9. Arrhenius plot for ETBE synthesis. 